\title{
Inhibitory effect of an endophytic fungus, Neotyphodium lolii, on the feeding and survival of Ostrinia furnacalis (Guenee) (Lepidoptera: Pyralidae) and Sesamia inferens (Walker) (Lepidoptera: Noctuidae) on infected Lolium perenne
}

\author{
Takuya ShibA* and Koya Sugawara \\ National Institute of Livestock and Grassland Science; Nasushiobara, Tochigi 329-2793, Japan \\ (Received 14 May 2009; Accepted 16 November 2009)
}

\begin{abstract}
To examine the feasibility of using endophytic fungi (/endophyte) as biological control agents against insect pests of host plants, the effect of Neotyphodium lolii, an endophyte living in perennial ryegrass, Lolium perenne L., was studied using two species of caterpillars: the Oriental corn borer, Ostrinia furnacalis (Guenee) (Lepidoptera: Pyralidae) and the pink borer, Sesamia inferens (Walker) (Lepidoptera: Noctuidae). Choice and no-choice feeding tests using endophyte-infected and endophyte-free clonal L. perenne indicate that endophyte-infected L. perenne have excellent resistance to $O$. furnacalis and $S$. inferens. Larvae of $O$. furnacalis significantly preferred endophyte-free to endophyte-infected grass. The ratio of surviving insects rapidly declined on infected grass and the survival curve on infected grass was similar to that of larvae of the no-food control. A similar trend occurred with $S$. inferens. These results indicate that $N$. lolii-infected $L$. perenne contains strong deterrent or toxic effects that affect $O$. furnacalis and $S$. inferens feeding and survival.
\end{abstract}

Key words: Neotyphodium endophyte; plant symbiotic fungi; insect resistance; Ostrinia furnacalis; Sesamia inferens

\section{INTRODUCTION}

Grass species of the subfamily Pooideae, including important forage and turf grass species, are often associated with fungal symbionts (endophytes) of the genera Neotyphodium (asexual/imperfect fungi) or their close sexual relative (/related fungi with sexual reproduction), Epichloë (Ascomycota: Clavicipitaceae) (Clay and Schardl, 2002). This symbiotic relationship has been receiving attention as the presence of the endophytes is sometimes linked with health problems in livestock fed on infected plants, examples of which are ryegrass staggers in perennial ryegrass, Lolium perenne L. (Fletcher and Harvey, 1981) and fescue toxicosis in tall fescue, Lolium arundinaceum (Schreb.) S.J. Darbyshire (syn. Festuca arundinacea Schreb.) (Bacon et al., 1977). Several beneficial effects of the fungi on host plants are also present. Increased tolerance for abiotic and biotic stresses, such as drought and insect pests, has been well documented (Breen, 1994; Clay and Schardl, 2002).

One of the most beneficial effects conferred by endophytes on their host grasses is the production of toxins and feeding deterrents that reduce insect herbivory. For example, infection by Neotyphodium lolii (Latch, Christensen and Samuels) Glenn, Bacon and Hanlin of L. perenne deters the Argentine stem weevil, Listronotus bonariensis (Kuschel), an insect pest that causes severe damage to this important forage grass (Rowan and Gaynor, 1986). In most areas of New Zealand, endophytic resistance to insects is so important that the persistence and productivity of $L$. perenne pastures is often poor unless a high percentage of plants are infected with N. lolii (Popay et al., 1999). In Japan, a positive association between resistance to the rice leaf bug, Trigonotylus caelestialium (Kirkaldy), and the presence of Neotyphodium endophytes in

* To whom correspondence should be addressed at: E-mail: takuyas@affrc.go.jp DOI: $10.1303 /$ aez.2010.225 
Lolium species was demonstrated recently (Shiba and Sugawara, 2005, 2009).

Resistance to more than 30 species of insects have been found to be associated with endophyteinfected $L$. perenne and $L$. arundinaceum, or by bioassaying the compounds produced by the endophyte in those plants (Latch, 1993; Breen, 1994); however, the responses of the insect to endophyteinfected grass differ depending on insect species (Latch, 1993; Breen, 1994). In view of the potential application of endophytic fungi as biological control agents against insect pests of their host plants, together with their impact on the agroecosystem surrounding them, detailed studies are needed to elucidate the effect of grass endophytes for insects species fed on their host. Furthermore, research into endophyte effects on insect pests in Japanese meadows are scarce. The objective of this study was to investigate the inhibitory effect of $N$. lolii-infected $L$. perenne on the feeding and survival of the Oriental corn borer, Ostrinia furnacalis (Guenee) (Lepidoptera: Pyralidae) and the pink borer, Sesamia inferens (Walker) (Lepidoptera: Noctuidae), generalist caterpillars that readily consume gramineous plants in Japanese meadows.

\section{MATERIALS AND METHODS}

Insects. Larvae of $O$. furnacalis and $S$. inferens were collected in the experimental fields of the $\mathrm{Na}$ tional Institute of Livestock and Grassland Science (NILGS) at Nasushiobara in Tochigi prefecture, Japan, and cultured on the corn stover, from which adult moths emerged and eggs were collected. The eggs of $O$. furnacalis oviposited on the surface of the corn stover, and the eggs of $S$. inferens oviposited in the corn leaf sheath were placed on moist filter paper in plastic Petri dishes $(90 \mathrm{~mm}$ diameter, $14 \mathrm{~mm}$ depth). First-instar larvae were used for bioassay studies within 12 hours after hatching.

Plants. The L. perenne clone, KE $+1996-7$, was used in the experiments. The clone was derived from an endophyte-free forage-type cultivar, "Kiyosato" and was inoculated as a seedling with a $N$. lolii isolate (Koga et al., 1997). The presence of the Neotyphodium endophyte in this clone has been regularly confirmed by microscopic observation of tillers (Fig. 1). As an endophyte-free control plant, the same grass clone from which the endophyte had been eradicated by fungicide treatment was

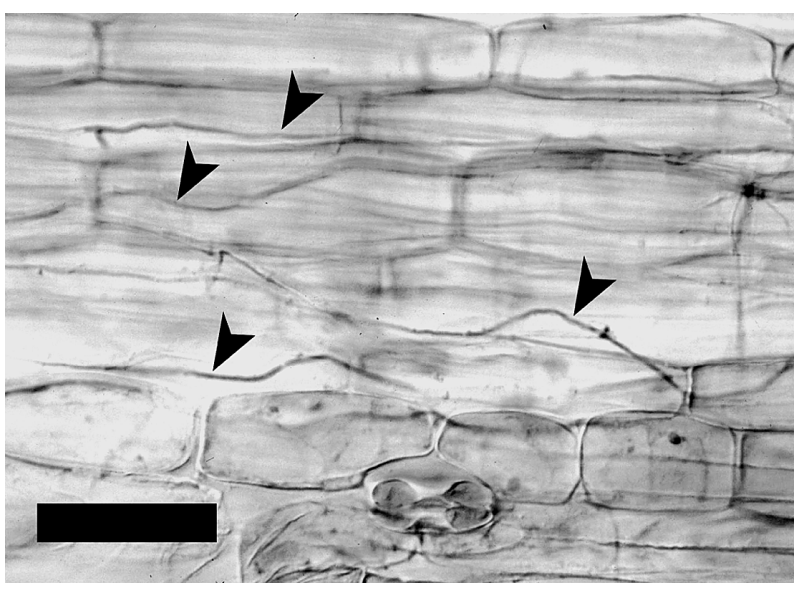

Fig. 1. Mycelium of Neotyphodium lolii (arrowheads) in a leaf sheath of the Lolium perenne clone (KE+1996-7) used in the experiments, stained by lactic acid containing $0.1 \%(\mathrm{w} / \mathrm{v})$ acid fuchsin. Bar: $100 \mu \mathrm{m}$.

used. The endophyte-free plant was produced in 1997, following the procedure developed by Shimanuki and Sato (1983). Both clones have been maintained through vegetative propagation as experimental lines in NILGS. For this study, both clones were increased by splitting and were maintained in pots filled with granulated soil (Kureha Engei-baido; Kureha Chemical Industry, Tokyo, Japan) in a growth cabinet $\left(20^{\circ} \mathrm{C}, 12 \mathrm{~L} 12 \mathrm{D}\right)$, providing leaves for insect-feeding experiments.

Choice test. The choice test was conducted with $O$. furnacalis and $S$. inferens to determine whether they showed any preference for endophyte-free $L$. perenne leaves compared with endophyte-infected leaves. Segments of fresh leaves, approximately 4-5 cm long, were obtained from endophyte-free and endophyte-infected plants and placed side-byside on moistened filter paper in $90 \mathrm{~mm}$ plastic Petri dishes. The widths of leaf blades of both plants were approximately $4-5 \mathrm{~mm}$, and did not differ between treatments. Five first-instar larvae were placed in the center of each dish using a paintbrush and the dishes were then sealed with Parafilm M film (Pechiney Plastic Packaging, Chicago) to prevent escape. The dishes were kept in a growth cabinet at $25^{\circ} \mathrm{C}$ and illuminated from the top by fluorescent lamps (16L8D). The number of insects present on each piece of leaf was counted after $1,2,4,8$, and $24 \mathrm{~h}$. The preference was calculated by dividing the number of insects on an infected leaf by the total number in each Petri dish (larvae with no specific orientation were 
ignored). Ten dishes were used for each treatment and considered as experimental replications.

No-choice test. To determine the effect of endophyte-infected tissues on $O$. furnacalis and $S$. inferens, we conducted a no-choice test with their firstinstar larvae. Each larva was transferred to a 90 $\mathrm{mm}$ plastic Petri dish containing ample leaf blades for insect growth from an endophyte-infected $L$. perenne or endophyte-free control. Larvae were also placed in Petri dishes with moistened filter paper alone as a no-food control. The dishes were kept in a growth cabinet at $25^{\circ} \mathrm{C}$ and illuminated from the top (16L8D). At 24-h intervals, the dishes were examined to determine the survival and development of the insects. Insects were considered dead if they did not show any response to prodding with a paintbrush, and after each $24 \mathrm{~h}$ period, surviving insects were transferred to fresh plant tissue of the same infection status. The assays were terminated at day 14. Twenty-seven insects were tested for each treatment of each insect species.

Statistics. Statistical analyses were performed using JMP version 7.0.2 (SAS Institute, Cary, NC, USA). In the no-choice feeding assay, longevity was analyzed using survival analysis. We estimated the survival curves for each treatment group with the Kaplan-Meier method. Differences in survival curves for each treatment were analyzed with a log-rank test. We then estimated the quantitative effect of endophyte-presence on survival with Cox's proportional hazards analysis (Cox, 1972). The quantitative effect of a variable is expressed as the risk ratio, which characterizes the risk of death in the endophyte-infected group in comparison to the control group: a risk ratio of 1 indicates that endophyte presence has no influence on survival, a value greater than 1 indicates a higher risk, and lower than 1 indicates a reduced risk of death.

In the feeding preference assay, the data were analyzed by the Wilcoxon matched-pairs signedranks test.

\section{RESULTS}

\section{Choice test}

In the choice tests using $O$. furnacalis first-instar larvae, significantly more larvae were present on endophyte-free leaves than on endophyte-infected leaves (Figs. 2 and 3). This trend became stronger over time, and the mean percentage of larvae found

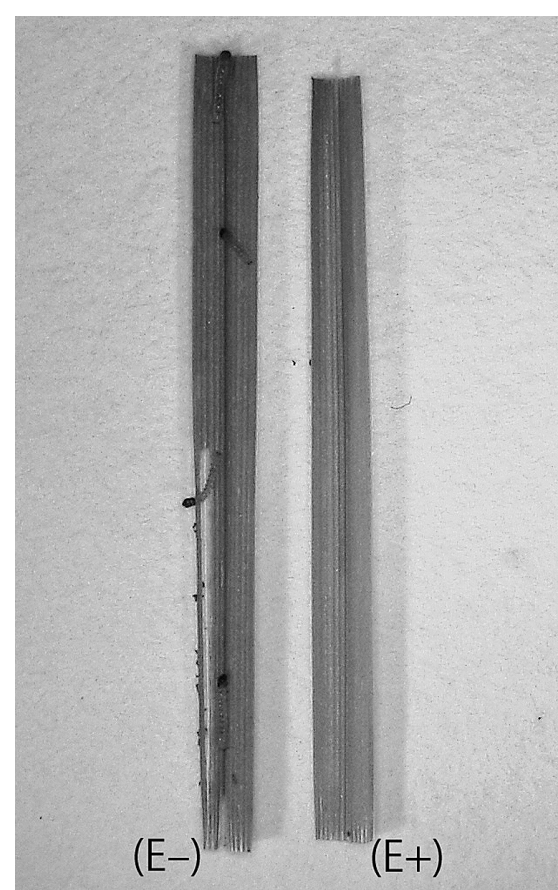

Fig. 2. Choice test using first instar larvae of Ostrinia furnacalis. The larvae did not choose the leaf blade of Lolium perenne infected with Neotyphodium lolii $(\mathrm{E}+)$, and fed only on the uninfected leaf $(\mathrm{E}-)$. The photograph was taken 8 hours after placement.

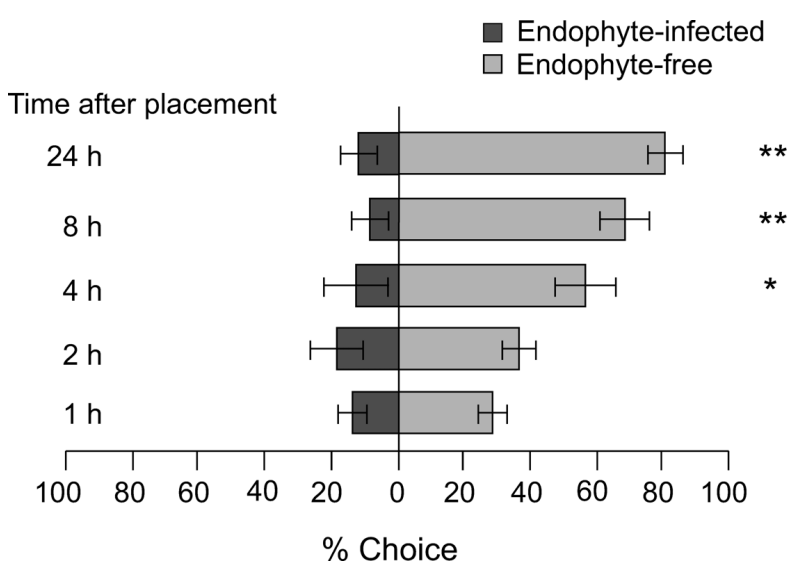

Fig. 3. The effect of Neotyphodium lolii infection on the choice of Ostrinia furnacalis first-instar larvae in feeding tests using Lolium perenne (mean $\pm \mathrm{SE}, n=10$ groups of five insects). Only larvae that were present on infected or endophytefree leaves at the time of observation were counted. Asterisks indicate a significant difference by Wilcoxon matched-pairs signed-ranks test $(* p<0.05 ; * * p<0.01)$.

on uninfected leaves reached $80.0 \pm 16.3 \%$ (mean \pm $\mathrm{SE}$ ), whereas $12.0 \pm 5.3 \%$ on infected leaves, in $24 \mathrm{~h}$ (significant difference in Wilcoxon matchedpairs signed-ranks test, $p<0.01$ ). The remaining $8.0 \%$ showed no feeding preference. A similar ten- 
dency was observed in the tests using $S$. inferens first-instar larvae (Fig. 4). Almost all larvae were found on uninfected leaves after $24 \mathrm{~h}$ (endophytefree, $92.0 \pm 3.3 \%$; endophyte-infected, $6.0 \pm 3.1 \%$; significant in Wilcoxon matched-pairs signed-ranks test, $p<0.01)$.

\section{No-choice test}

In feeding trials using first-instar larvae of $O$. furnacalis and leaves of the endophyte-infected clone, larvae ate small amounts of infected leaf blades and eventually died. No insects developed

Endophyte-infected $\square$ Endophyte-free

Time after placement

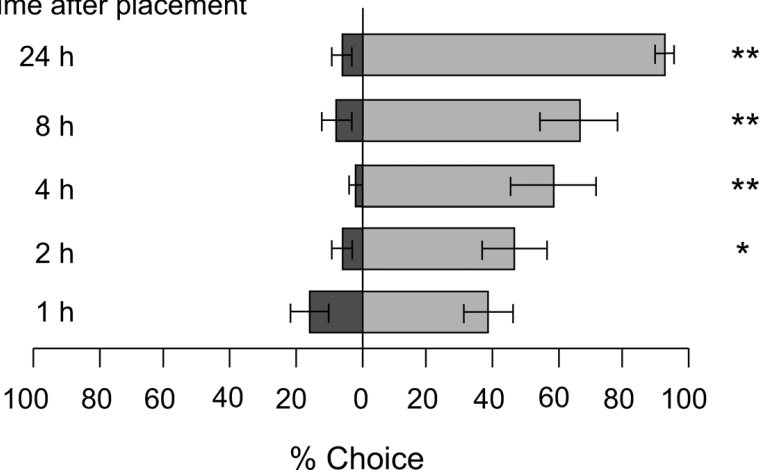

Fig. 4. The effect of Neotyphodium lolii infection on the choice of Sesamia inferens first-instar larvae in feeding tests using Lolium perenne (mean $\pm \mathrm{SE}, n=10$ groups of five insects). Only larvae that were present on infected or endophytefree leaves at the time of observation were counted. Asterisks indicate a significant difference by Wilcoxon matched-pairs signed-ranks test $(* p<0.05 ; * * p<0.01)$. beyond the first instar and all insects died within 6 days. The survival curve of larvae on infected leaves was similar to that of larvae with no food. In contrast, $74.1 \%$ larvae on endophyte-free leaves were alive after 14 days (Fig. 5) and almost all living larvae reached the fourth-instar stage. The logrank test, used to compare survival curves from the 3 treatments (endophyte-infected, endophyte-free, no-food), showed a statistically significant difference between these treatments $\left(\chi^{2}=72.1, p<\right.$ $0.001)$. Further investigation with the Cox's proportional hazards model indicated that larvae on endophyte-infected leaves were 27.50 times more likely to die than those on the endophyte-free control and the ratio was not significantly different relative to that of the no-food control (Table 1).

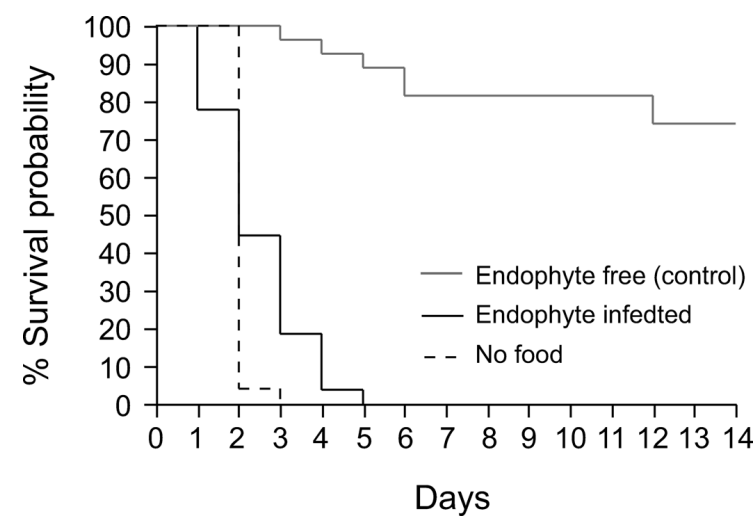

Fig. 5. Survival probabilities of Ostrinia furnacalis first instars ( $n=27 /$ treatment) reared from egg hatch on leaves of Lolium perenne with or without endophyte infection, and the no-food control.

Table 1. Cox's proportional hazard analysis of Ostrinia furnacalis and Sesamia inferens larvae fed on endophyte-infected Lolium perenne in comparison to the two control groups

\begin{tabular}{|c|c|c|c|c|c|c|}
\hline & Coefficient $(\beta)$ & $\begin{array}{l}\text { Standard } \\
\text { error }\end{array}$ & $\begin{array}{l}\text { Likelihood } \\
\text { ratio }\left(\chi^{2}\right)\end{array}$ & $p$-value & Risk ratio $^{\mathrm{a}}$ & $\begin{array}{l}95 \% \text { confidence }^{\text {cond }} \\
\text { interval }^{\text {b }}\end{array}$ \\
\hline \multicolumn{7}{|l|}{$\begin{array}{l}\text { Ostrinia furnacalis fed on } \\
\text { endophyte-infected leaf }\end{array}$} \\
\hline vs. fed on endophyte-free leaf & 3.31 & 0.65 & 47.62 & $<0.001$ & 27.50 & $8.86-123.17$ \\
\hline vs. no-food control & -0.39 & 0.32 & 1.52 & 0.22 & 0.68 & $0.36-1.26$ \\
\hline \multicolumn{7}{|l|}{$\begin{array}{l}\text { Sesamia inferens fed on } \\
\text { endophyte-infected leaf }\end{array}$} \\
\hline vs. fed on endophyte-free leaf & 4.33 & 1.04 & 53.43 & $<0.001$ & 75.74 & $15.00-1385.20$ \\
\hline vs. no-food control & -0.05 & 0.27 & 0.04 & 0.84 & 0.95 & $0.55-1.62$ \\
\hline
\end{tabular}




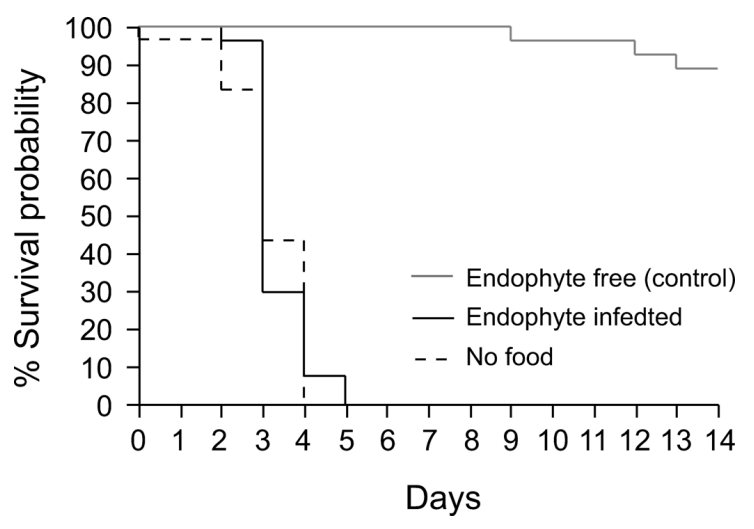

Fig 6. Survival probabilities of Sesamia inferens first instars $(n=27 /$ treatment) reared from egg hatch on leaves of Lolium perenne with or without endophyte infection, and the no-food control.

A similar trend occurred with $S$. inferens larvae. The survival of insects on endophyte-free leaves over time was very high $(85.1 \%$ survived and reached the third or fourth-instar stage after 14 days), whereas a rapid decline was observed on endophyte-infected segments, with all larvae being dead at the first-instar stage by 6 days (Fig. 6) (logrank test, $\left.\chi^{2}=71.9, p<0.001\right)$. The risk of death for the endophyte-infected group was 75.74 times higher than that for larvae fed on endophyte-free leaves, and not significantly different from the nofood control (Table 1).

\section{DISCUSSION}

$N$. lolii-infected $L$. perenne used in this study (KE+1996-7) are known to have marked levels of resistance to the bluegrass webworm, Parapediasia teterrella (Zincken) and T. caelestialium (Koga et al., 1997; Shiba and Sugawara, 2005). The experiments in our current study indicate that this plant also has excellent resistance to $O$. furnacalis and $S$. inferens and it means that the prevention of feeding damage by these insects on $L$. perenne plants is possible with the endophyte.

Larvae of $O$. furnacalis and $S$. inferens significantly preferred endophyte-free to endophyte-infected plants and ate smaller amounts of infected leaf blades. The ratios of surviving insects rapidly declined on infected leaves. Our results indicated that starvation of the insects was initiated by the endophyte; the pattern of survival curves on infected grasses was almost the same with the survival curves of the no-food control. It is possible that chemicals toxic to $O$. furnacalis and $S$. inferens are present in $N$. lolii infected $L$. perene, but the effect observed in the trial can be attributed entirely to feeding deterrence. Enhanced resistance to those insects observed in this study was similar to the data reported from the same plant with other insects species (Koga et al., 1997; Shiba and Sugawara, 2005). This indicates that $L$. perenne with $N$. lolii may have strong feeding deterrent ability that results in the starvation of a broad spectrum of insects.

Endophyte-mediated resistance to herbivores is considered to be effected largely by the types of alkaloids produced by endophytes in host grasses (Clay and Schardl, 2002). Four classes of alkaloids have been commonly associated with Neotyphodium endophytes and have a range of adversary effects on herbivores. Ergovaline (ergot alkaloids) and lolitrem B (indole diterpene) are toxic to mammals and adversely affect grazing animals (Gallagher et al., 1981; Porter et al., 1981). Peramine (pyrrolopyrazine) is known to be an insect-feeding deterrent (Rowan and Gaynor, 1986). Loline alkaloids (pyrrolizidines) are broadly insecticidal (Bush et al., 1997). The presence of these alkaloids in host plants is dependent on the endophyte species and strain (Christensen et al., 1993); for example, L. perenne with $N$. lolii can accumulate lolitrem B, ergovaline, and peramine (Bush et al., 1997). Meadow fescue, L. pratense (Huds.) (syn. Festuca pratensis Huds.), in symbiosis with $N$. uncinatum (Gams, Petrini and Schmidt) Glenn, Bacon and Hanlin, produces only lolines (Bush et al., 1997). Italian ryegrass, L. multiflorum Lam, in symbiosis with $N$. occultans Moon, Scott and Christensen produces lolines and peramine (Sugawara et al., 2006).

Since some $N$. lolii strains make ergovaline, lolitrem B, and peramine in their host plants (Clay and Schardl, 2002), the N. lolii-infected L. perenne clone used in this study may contain these three chemicals, giving rise to the resistance to $O$. furnacalis and $S$. inferens. There are reports indicating that ergot alkaloids and lolitrems can cause adverse effects on insect survival and feeding (Prestidge and Gallagher, 1988; Potter et al., 2008). Peramine is the major insect-feeding deterrent isolated from Neotyphodium-infected grasses (Rowan and Gaynor, 1986). The possibility cannot be rejected that other minor, or unknown, chemicals from the 
endophyte are associated with the resistance observed in this study. Artificial diet containing paxilline, an indole diterprnoid found in N. loliiinfected $L$. perenne, has been reported to reduce the development and survival of Spodoptera frugiperda larvae (Dowd et al., 1988). It is also reported that an $N$. lolii strain, which produces none of those common alkaloids in host grasses, has broad spectrum activity against insects (Popay and Wyatt, 1995; Jensen and Popay, 2004; Popay et al., 2004). Further studies are needed to identify which alkaloids are present in the grass used in this experiments, and to determine whether the repelling effect observed was related to known chemicals (such as ergovaline, lolitrem B and peremine), or other alkaloids.

The endophyte-infected $L$. perenne used in this experiment may not be suitable for pasture use since it may contain mammalian toxins; however, it is possible to artificially isolate and re-inoculate the fungi to make novel associations of plants and fungi (Latch and Christensen, 1985), and cultivars of forage grasses artificially inoculated with livestock-friendly strains of Neotyphodium species are now commercially available in Australia, New Zealand, and the USA (Bouton and Easton, 2005; Easton and Tapper, 2005; Wheatley, 2005). If we can select endophyte strains, or infected grasses with insect-repelling effects but not with mammal toxicity, it will assist the breeding of forage grasses free from insect pest problems, such as attacks from $O$. furnacalis and $S$. inferens. Research is now in progress to identify the mechanisms by which this Neotyphodium endophyte deters the feeding of those insects.

\section{ACKNOWLEDGMENTS}

Authors are grateful to Kenichi Kanda, National Institute of Livestock and Grassland Science, Japan for his help in insect collection. We also thank Michael J. Christensen, AgResearch Grassland Research Center, New Zealand for his helpful advice on the preparation of the manuscript.

\section{REFERENCES}

Bacon, C. W., J. K. Porter, J. D. Robbins and E. S. Luttrell (1977) Epichloë typhina from toxic tall fescue grasses. Appl. Environ. Microbiol. 34: 576-581.

Bouton, J. and S. Easton (2005) Endophytes in forage cultivars. In Neotyphodium in Cool-Season Grasses (C. A. Roberts, C. P. West and D. E. Spiers, eds.). Blackwell Publishing, Ames, IA, USA, pp. 327-340.

Breen, J. P. (1994) Acremonium endophyte interactions with enhanced plant resistance to insects. Annu. Rev. Entomol. 39: 401-423.

Bush, L. P., H. H. Wilkinson and C. L. Schardl (1997) Bioprotective alkaloids of grass-fungal endophyte symbioses. Plant Physiol. 114: 1-7.

Christensen, M. J., A. Leuchtmann, D. D. Rowan and B. A. Tapper (1993) Taxonomy of Acremonium endophytes of tall fescue (Festuca arundinacea), meadow fescue $(F$. pratensis), and perennial rye-grass (Lolium perenne). Mycol. Res. 97: 1083-1092.

Clay, K. and C. Schardl (2002) Evolutionary origins and ecological consequences of endophyte symbiosis with grasses. Am. Nat. 160: S99-S127.

Cox, D. R. (1972) Regression models and life-tables $J$. Roy. Stat. Soc. B 34: 187-220.

Dowd, P. F., R. J. Cole and R. F. Vesonder (1988) Toxicity of selected tremorgenic mycotoxins and related compounds to Spodoptera frugiperda and Heliothis zea. J. Antibiot. 41: $1868-1872$.

Easton, S. and B. Tapper (2005) Neotyphodium research and application in New Zealand. In Neotyphodium in CoolSeason Grasses (C. A. Roberts, C. P. West and D. E. Spiers, eds.). Blackwell Publishing, Ames, IA, USA, pp. $35-42$.

Fletcher, L. R. and I. C. Harvey (1981) An association of a Lolium endophyte with ryegrass staggers. New Zeal. Vet. J. 29: 185-186.

Gallagher, R. T., E. P. White and P. H. Mortimer (1981) Ryegrass staggers: Isolation of potent neurotoxins lolitrem A and lolitrem B from staggers-producing pastures. New Zeal. Vet. J. 29: 189-190.

Jensen, J. G. and A. J. Popay (2004) Perennial ryegrass infected with AR37 endophyte reduces survival of porina larvae. N. Z. Plant Protect. 57: 323-328.

Koga, H., Y. Hirai, K. Kanda, T. Tsukiboshi and T. Uematsu (1997) Successive transmission of resistance to bluegrass webworm to perennial ryegrass and tall fescue plants by artificial inoculation with Acremonium endophytes. JARQ 31: 109-115.

Latch, G. C. M. (1993) Physiological interactions of endophytic fungi and their hosts. Biotic stress tolerance imparted to grasses by endophytes. Agr. Ecosyst. Environ. 44: $143-156$.

Latch, G. C. M. and M. J. Christensen (1985) Artificial infection of grasses with endopytes. Ann. Appl. Biol. 107: 17-24.

Popay, A. J. and R. T. Wyatt (1995) Resistance to Argentine stem weevil in perennial ryegrass infected with endophytes producing different alkaloids. Proc. 48th N. Z. Plant Prot. Conf. 229-236.

Popay, A. J., D. E. Hume, J. G. Baltus, G. C. M. Latch, B. A. Tapper, T. B. Lyons, B. M. Cooper, C. G. Pennell, J. P. J. Eerence and S. L. Marshall (1999) Field performance of perennial ryegrass (Lolium perenne) infected with toxin-free fungal endophytes (Neotyphodium spp.). In Grassland Research and Practice Series. Vol. 7 (D. R. Woodfield and C. Matthew, eds.). New Zealand Grassland Association Inc., Wellington, New Zealand, pp. $113-122$ 
Popay, A. J., W. B. Silvester and P. J. Gerard (2004) New endophyte isolate suppresses root aphid, Aploneura lentisci, in perennial ryegrass. In Proceedings 5th International Symposium on Neotyphodium/Grass Interactions. Fayetteville, AR, USA, p. 317.

Porter, J. K., C. W. Bacon, J. D. Robbins and D. Betowski (1981) Ergot alkaloid identification in Clavicipitaceae systemic fungi of pasture grasses. J. Agric. Food Chem. 29: 653-657.

Potter, D. A., J. T. Stokes, C. T. Redmond, C. L. Schardl and D. G. Panaccione (2008) Contribution of ergot alkaloids to suppression of a grass-feeding caterpillar assessed with gene knockout endophytes in perennial ryegrass. Entomol Exp. Appl. 126: 138-147.

Prestidge, R. A. and R. T. Gallagher (1988) Endophyte fungus confers resistance to ryegrass: Argentine stem weevil larval studies. Ecol. Entomol. 13: 429-435.

Rowan, D. D. and D. L. Gaynor (1986) Isolation of feeding deterrents against argentine stem weevil from ryegrass infected with the endophyte Acremonium loliae. J. Chem. Ecol. 12: 647-658.

Shiba, T. and K. Sugawara (2005) Resistance to the rice leaf bug, Trigonotylus caelestialium, is conferred by Neotyphodium endophyte infection of perennial ryegrass, Lolium perenne. Entomol Exp. Appl. 115: 387-392.

Shiba, T. and K. Sugawara (2009) Fungal loline alkaloids in grass-endophyte associations confer resistance to the rice leaf bug, Trigonotylus caelestialium. Entomol. Exp. Appl. 130: 55-62.

Shimanuki, T. and T. Sato (1983) Therapeutic effect of systemic fungicides against the choke disease of timothy caused by Epichloë typhina (Pers. ex Fr.) Tul. Res. Bull. Hokkaido Natl. Agr. Exp. Stat. 138: 99-104 (in Japanese with English summary).

Sugawara, K., T. Inoue, M. Yamashita and H. Ohkubo (2006) Distribution of the endophytic fungus, Neotyphodium occultans in naturalized Italian ryegrass in western Japan and its production of bioactive alkaloids known to repel insect pests. Grassl. Sci. 52: 147-154.

Wheatley, W. M. (2005) Endophytes, quality assurance, and the seed trade in eastern Australia. In Neotyphodium in Cool-Season Grasses (C. A. Roberts, C. P. West and D. E. Spiers, eds.). Blackwell Publishing, Ames, IA, USA, pp. 351-360. 